\title{
Relationship between hemodialysis and health-related quality of life: a cross-sectional study of diagnosis and duration of hemodialysis
}

\author{
Shinichi Noto ${ }^{1 *} \mathbb{0}$, Masashi Miyazaki ${ }^{2}$, Hidemi Takeuchi ${ }^{3}$ and Shinya Saito ${ }^{4}$
}

\begin{abstract}
Background: Hemodialysis is a medical technology implemented for various renal diseases and has a significant budget impact in Japan. Hemodialysis also affects health-related quality of life, as it interferes with daily life, but the effect of diagnosis and duration of hemodialysis is not clear. The purpose of this study was to examine the impact of hemodialysis on health-related quality of life, with a focus on diagnosis and duration of hemodialysis.

Methods: We conducted EQ-5D-5L surveys among hemodialysis patients at a single hemodialysis hospital between November 2015 and September 2017 and used a scoring algorithm that was developed in Japan to calculate the scores.

Results: A total of 274 subjects without missing data were included in the data analysis. The mean score of the entire group was $0.772 \pm 0.215$. Compared with other domains, pain/discomfort had the highest percentage of problems (59.1\%). There were no differences in the distributions with respect to diagnostic names in any domain. Multiple regression analysis showed that hemodialysis duration was the only explanatory variable that had a mild significant effect on EQ-5D-5L scores, but it was not large.

Conclusions: QOL measured using the EQ-5D-5L survey score was not affected by age, gender, or diagnosis but was affected by hemodialysis duration. Future studies are needed to investigate the impact of prolonged hemodialysis on health-related quality of life.
\end{abstract}

Keywords: Quality of life, Duration of hemodialysis, Hemodialysis, EQ-5D-5L

\section{Background}

In Japan, the number of dialysis patients and associated medical costs have been increasing owing to the aging of the population. The patient numbers approached 340,000 in 2018, an increase of approximately $60 \%$ since 2000 . Medical expenses for dialysis are approximately 1.7 trillion Yen, which accounts for about $4 \%$ of total medical

*Correspondence: noto@nuhw.ac.jp

1 Department of Rehabilitation, Niigata University of Health and Welfare, 1398 Shimamicho, Kita-ku, Niigata 950-1398, Japan

Full list of author information is available at the end of the article expenses [1]. From the start of the 2019 fiscal year, a costeffectiveness evaluation for medical technologies was introduced in Japan. The efficiency of various medical technologies is expected to be discussed in the future. To ensure the successful implementation of the health technology assessment in Japan, which includes a cost-effectiveness assessment, the need to collect basic data on the costs and effectiveness of medical treatment, as well as preference-based quality of life (QOL) data for various diseases, i.e., efficacy values, is evident. original author(s) and the source, provide a link to the Creative Commons licence, and indicate if changes were made. The images or other third party material in this article are included in the article's Creative Commons licence, unless indicated otherwise in a credit line to the material. If material is not included in the article's Creative Commons licence and your intended use is not permitted by statutory regulation or exceeds the permitted use, you will need to obtain permission directly from the copyright holder. To view a copy of this licence, visit http://creativecommons.org/licenses/by/4.0/. The Creative Commons Public Domain Dedication waiver (http://creativeco mmons.org/publicdomain/zero/1.0/) applies to the data made available in this article, unless otherwise stated in a credit line to the data. 
According to a systematic review conducted by Liem et al. [2], the efficacy values for dialysis had $95 \%$ confidence intervals (CIs) of 0.54-0.68, 0.57-0.92, and 0.49-0.62 in the Time Trade-off, Standard Gamble, and EuroQoL five-dimensional (EQ-5D) scores, respectively. Besides these measures, the Health Utilities Index [3] and six-dimensional health state short form [4-6] were used. However, the impact of dialysis duration on QOL has not been completely elucidated, as Phair et al. [7] reported a decrease from 0.73 at baseline to 0.67 at 1 -year follow-up, while Yang et al. $[8,9]$ reported that dialysis lasting more than 3.5 years had no impact on QOL.

It is well known that utility values vary depending on the measurement method and scale used. The EQ-5D is a measurement tool developed by the EuroQol Group. It is the most widely used indirect preference-based measure of the QOL in the world [10]. There are two variants of the EQ-5D, namely the 3-level EQ-5D and 5-level EQ-5D (EQ-5D-5L), and its scoring algorithm differs from country to country. Therefore, it is impossible to compare reports using these parameters in a uniform manner.

In addition, the Official Guidelines for the Economic Evaluation of Drugs/Medical Devices in Japan [11], which were developed for measuring efficacy values, recommend the use of a preference-based measure developed by the time trade-off method. Currently, the EQ-5D-5L is the only tool conforming to this recommendation. With an increased need for evaluation of health economics for various disease areas in the future, it would be meaningful to elucidate the effects of hemodialysis.

There are certainly several previous studies using the EQ-5D in Japan. Takura et al. [12] showed that the utility values of EQ-5D were lower in patients with diabetic nephropathy than in those with other diseases. Shimizu et al. [13] also reported that the decline in the QOL of dialysis patients was related to the decline in the ability to walk and increase in age. However, the effect of dialysis on EQ-5D utility values is not completely understood. In addition, the impact of hemodialysis on QOL (i.e., on the domains of EQ-5D-5L) of hemodialysis patients remains unclear. This study aimed to investigate the effects of primary disease and hemodialysis duration on utility values and distribution characteristics of EQ-5D-5L scores in hemodialysis patients.

\section{Methods}

\section{Study sample}

In this single-center study, we conducted a survey among dialysis patients at the Renal Failure Center of Saiwaicho Memorial Hospital in Okayama Prefecture between November 2015 and September 2017. Okayama Prefecture is located in the Kinki region and with a population of approximately 2 million people, it is the 20th largest municipality of the 47 prefectures in Japan. Saiwaicho
Memorial Hospital is a dialysis hospital with 80 dialysis beds. The inclusion criteria were as follows: a definite diagnosis, age of at least 20 years, no cognitive impairment, and the ability to answer a self-administered questionnaire.

\section{Procedure}

The survey was first administered to consenting patients who were briefed by trained nurses. Patients responded to the EQ-5D-5L and EuroQol Visual Analogue Scale (EQ-VAS) on their own. Information regarding the patients' genders, ages, diagnoses, and dialysis durations was collected from medical records. The following classifications were used for diagnoses: chronic glomerulonephritis, diabetic nephropathy, nephrosclerosis, cystic kidney, pregnancy toxemia, and others.

\section{Measures}

Preference-based QOL was measured using the Japanese version of the EQ-5D-5L. The EQ-5D-5L is a tool that comprises five domains for measuring the QOL: mobility, personal care, daily activities, pain/discomfort, and anxiety/stifling. Each domain has five levels: no, slight, moderate, severe, and extreme problems. It also includes EQ-VAS, which is a measure that uses a visual analog scale to indicate the health status of the day on a scale of $0-100$. A cross-sectional study on hemodialysis patients at Saiwaicho Memorial Hospital in Okayama Prefecture, Japan, which used the Japanese version of the scoring algorithm developed by Ikeda et al. [14], revealed that the best and worst health states, indicated by "11111" and “55555," respectively, were 1 and -0.003 , respectively.

\section{Ethical procedure}

We explained the purpose and methods of the study to the subjects and obtained their written consent. This study was approved by the Ethics Committee of Niigata University of Health and Welfare (No. 17560-150205).

\section{Statistical analysis}

Data are presented as mean \pm standard deviation. The $X^{2}$ test and analysis of variance were used to compare groups with respect to demographic factors. Spearman's rank correlation coefficient was used to assess the correlation between variables. Differences in quality of life by duration of dialysis were treated using a one-way analysis of variance. Finally, the multiple regression analysis was also performed to confirm the relationship between EQ5D-5L scores, EQ-VAS results, and other factors. SPSS Statistics 24 (International Business Machines Corporation, Armonk, NY, United States) was used for statistical analyses, and the significance level was set at $5 \%$. 


\section{Results}

\section{Subjects}

A total of 278 patients were included in this study, of whom 274 patients without missing data were included in the data analysis. The characteristics of the subjects are shown in Table 1 . The mean age of the subjects was $68.8 \pm 12.7$ years, and the male to female ratio was $173 / 101$. The disease breakdown for the subjects was as follows: chronic glomerulonephritis, diabetic nephropathy, nephrosclerosis, cystic kidney, pregnancy toxemia, and others in $82,96,40,12,6$, and 38 subjects, respectively $(30.0 \%, 35.0 \%, 14.5 \%, 4.4 \%, 2.2$, and $13.8 \%$, respectively).

\section{EQ-5D-5L scores}

The mean EQ-5D-5L score for the entire subject population was $0.772 \pm 0.215$ (Table 1). The mean scores for chronic glomerulonephritis, diabetic nephropathy, nephrosclerosis, cystic kidney, pregnancy toxemia, and others were $0.750 \pm 0.236,0.768 \pm 0.221,0.802 \pm 0.197$, $0.814 \pm 0.175,0.819 \pm 0.122$, and $0.787 \pm 0.207$, respectively; however, there were no significant differences in EQ-5 scores among these diseases. The differences in $\mathrm{D}-5 \mathrm{~L}$ scores were also not statistically significant $(p=0.779)$. The differences in the EQ-5D-5L scores for each age group were not statistically significant; the scores of $<59,60-69,70-79$, and $\geq 80$ years age group were $0.805 \pm 0.201, \quad 0.748 \pm 0.235, \quad 0.779 \pm 0.219$, and $0.780 \pm 0.202$, respectively $(p=0.506)$.

Figure 1 shows the distribution of responses with respect to domain. The findings were as follows: the proportions for "some kind of problem" of mobility, self-care, usual activities, pain/discomfort, and anxiety/depression were $50.3 \%, 28.1 \%, 48.9 \%, 59.1 \%$, and $31.4 \%$, respectively, in each domain. Pain/discomfort had the highest rate of reported problems. Table 2 also shows the distribution of EQ-5D-5L responses with respect to diagnostic names. There were no differences in the distributions with respect to diagnostic names in any domain.

\section{EQ-5D-5L VAS scores}

The mean EQ-5D-5L VAS score for the entire subject population was $69.8 \pm 21.0$ (Table 1). The mean scores for chronic glomerulonephritis, diabetic nephropathy, nephrosclerosis, cystic kidney, pregnancy toxemia, and other diseases were $70.9 \pm 20.8,71.2 \pm 19.7,69.9 \pm 24.8$, $61.1 \pm 23.3,68.7 \pm 22.5$, and $64.3 \pm 22.5$, respectively; however, we found that the differences in EQ-5D-5L VAS scores among the diseases were not statistically significant $(\mathrm{p}=0.584)$. The EQ-5D-5L and EQ-5D-5L VAS scores had a correlation coefficient of $r=-0.085$.

\section{The relationship between hemodialysis duration and EQ-5D-5L score}

Figure 2 shows the distribution of hemodialysis duration and EQ-5D-5L scores. Figure 3 also shows the EQ-5D-5L scores for each quintile of the hemodialysis period. In addition, Table 3 shows the differences in EQ-5D-5L scores by hemodialysis period. The EQ-5D-5L score was maintained near 0.8 if the duration of hemodialysis was less than 10 years, but after 10 years, the EQ-5D-5L score decreased. A one-way analysis of variance showed a significant difference $(p=0.001)$.

\section{Regression analysis}

Multiple regression analysis was performed on EQ5D-5L and EQ-5D-5L VAS scores, with each domain as an objective variable. The explanatory variables for the EQ-5D-5L score included gender, age, hemodialysis duration, and diagnosis. Only hemodialysis duration had

Table 1 Characteristics and EQ-5D-5L data of subjects

\begin{tabular}{|c|c|c|c|c|c|c|c|c|}
\hline & All $(n=274)$ & $\begin{array}{l}\text { Chronic } \\
\text { glomerulonephritis } \\
(n=82)\end{array}$ & $\begin{array}{l}\text { Diabetic } \\
\text { nephropathy } \\
(n=96)\end{array}$ & $\begin{array}{l}\text { Nephrosclerosis } \\
(n=40)\end{array}$ & $\begin{array}{l}\text { Cystic kidney } \\
(n=12)\end{array}$ & $\begin{array}{l}\text { Pregnancy } \\
\text { toxemia } \\
(n=6)\end{array}$ & $\begin{array}{l}\text { Others } \\
(n=38)\end{array}$ & $P$ value \\
\hline $\operatorname{Sex}(M / F)$ & $173 / 101$ & $43 / 39$ & $72 / 24$ & $24 / 16$ & $8 / 4$ & $0 / 6$ & $26 / 12$ & $<0.001$ \\
\hline Age (year) & $68.8 \pm 12.7$ & $67.5 \pm 11.1$ & $67.9 \pm 10.9$ & $79.7 \pm 11.9$ & $61.6 \pm 8.7$ & $68.8 \pm 7.8$ & $64.6 \pm 16.4$ & $<0.001$ \\
\hline Age $<59$ & 59 & 16 & 23 & 2 & 5 & 0 & 13 & $<0.001$ \\
\hline $60-69$ & 83 & 33 & 27 & 6 & 5 & 4 & 8 & \\
\hline $70-79$ & 71 & 22 & 31 & 6 & 2 & 1 & 9 & \\
\hline$\geq 80$ & 62 & 11 & 16 & 26 & 0 & 1 & 8 & \\
\hline $\begin{array}{l}\text { Duration of } \\
\text { hemodialysis } \\
\text { (y) }\end{array}$ & $8.0 \pm 9.1$ & $14.2 \pm 11.7$ & $5.2 \pm 4.3$ & $3.6 \pm 3.7$ & $7.9 \pm 8.2$ & $19.3 \pm 12.0$ & $4.3 \pm 7.0$ & $<0.001$ \\
\hline $\begin{array}{l}\text { EQ-5D-5L } \\
\text { score }\end{array}$ & $0.772 \pm 0.215$ & $0.750 \pm 0.236$ & $0.768 \pm 0.221$ & $0.802 \pm 0.197$ & $0.814 \pm 0.175$ & $0.819 \pm 0.122$ & $0.787 \pm 0.207$ & 0.779 \\
\hline EQ-5D-5L VAS & $69.8 \pm 21.0$ & $70.9 \pm 20.8$ & $71.2 \pm 19.7$ & $69.9 \pm 24.8$ & $61.1 \pm 23.3$ & $68.7 \pm 22.5$ & $64.3 \pm 22.5$ & 0.584 \\
\hline
\end{tabular}




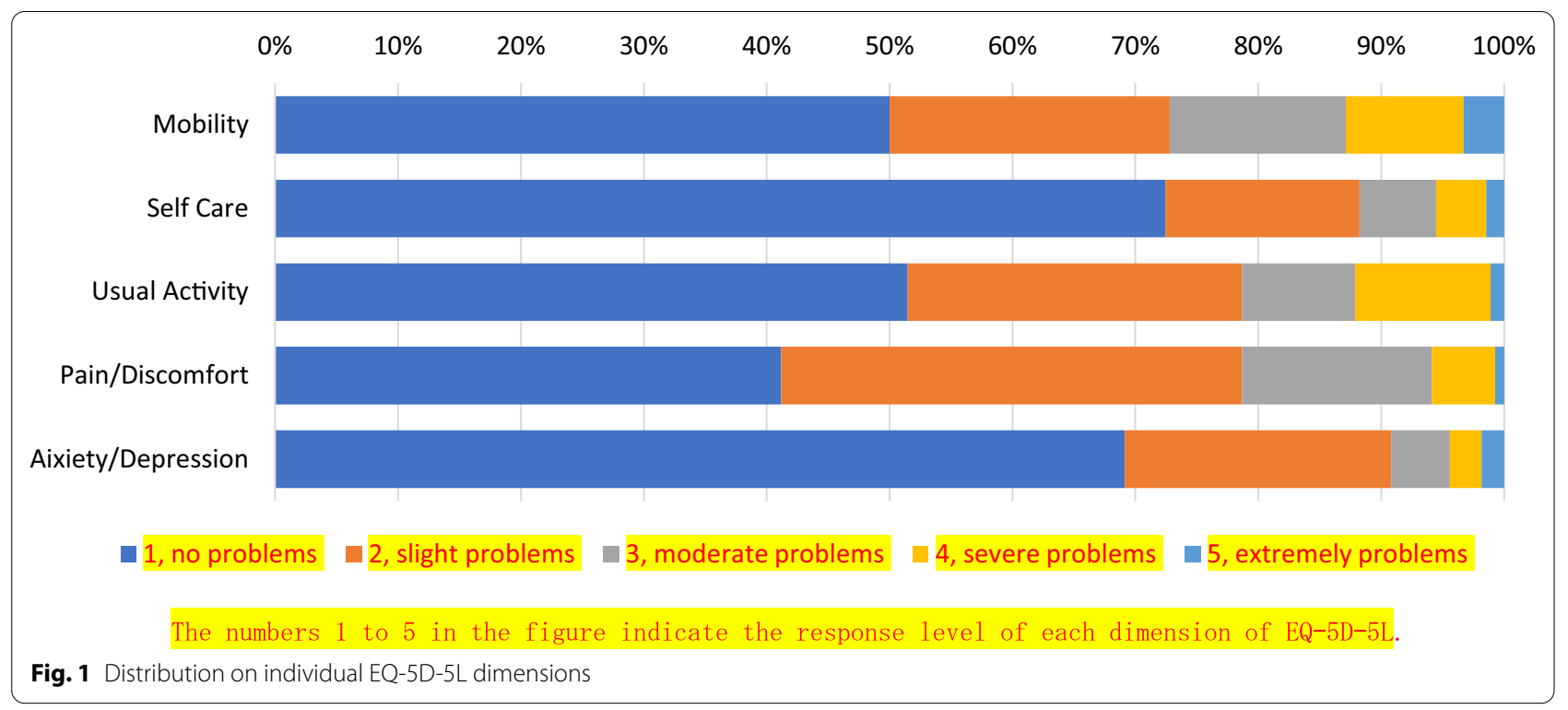

Table 2 Number of respondents at different levels in the EQ-5D-5L profile by diagnosis

\begin{tabular}{|c|c|c|c|c|c|c|c|c|}
\hline & Level & $\begin{array}{l}\text { Chronic } \\
\text { glomerulonephritis } \\
(n=82)\end{array}$ & $\begin{array}{l}\text { Diabetic } \\
\text { nephropathy } \\
(n=96)\end{array}$ & $\begin{array}{l}\text { Nephrosclerosis } \\
(n=40)\end{array}$ & $\begin{array}{l}\text { Cystic } \\
\text { kidney } \\
(n=12)\end{array}$ & $\begin{array}{l}\text { Pregnancy } \\
\text { toxemia } \\
(n=6)\end{array}$ & $\begin{array}{l}\text { Others } \\
(n=38)\end{array}$ & $P$ value \\
\hline \multirow[t]{5}{*}{ Mobility } & 1 & 42 & 44 & 22 & 5 & 3 & 20 & 0.745 \\
\hline & 2 & 15 & 25 & 8 & 5 & 1 & 10 & \\
\hline & 3 & 9 & 16 & 6 & 1 & 2 & 5 & \\
\hline & 4 & 10 & 8 & 4 & 1 & 0 & 3 & \\
\hline & 5 & 6 & 3 & 0 & 0 & 0 & 0 & \\
\hline \multirow[t]{5}{*}{ Self-care } & 1 & 57 & 69 & 33 & 9 & 5 & 26 & 0.919 \\
\hline & 2 & 13 & 14 & 4 & 2 & 1 & 9 & \\
\hline & 3 & 4 & 8 & 2 & 1 & 0 & 2 & \\
\hline & 4 & 6 & 3 & 1 & 0 & 0 & 1 & \\
\hline & 5 & 2 & 2 & 0 & 0 & 0 & 0 & \\
\hline \multirow[t]{5}{*}{ Usual activity } & 1 & 46 & 46 & 20 & 7 & 3 & 20 & 0.915 \\
\hline & 2 & 16 & 25 & 13 & 4 & 3 & 13 & \\
\hline & 3 & 8 & 12 & 3 & 0 & 0 & 2 & \\
\hline & 4 & 11 & 12 & 3 & 1 & 0 & 3 & \\
\hline & 5 & 1 & 1 & 1 & 0 & 0 & 0 & \\
\hline \multirow[t]{5}{*}{ Pain/discomfort } & 1 & 32 & 39 & 18 & 6 & 2 & 17 & 0.929 \\
\hline & 2 & 30 & 34 & 17 & 5 & 2 & 14 & \\
\hline & 3 & 13 & 17 & 3 & 1 & 2 & 6 & \\
\hline & 4 & 6 & 6 & 2 & 0 & 0 & 0 & \\
\hline & 5 & 1 & 0 & 0 & 0 & 0 & 1 & \\
\hline \multirow[t]{5}{*}{ Anxiety/depression } & 1 & 53 & 69 & 27 & 8 & 5 & 28 & 0.916 \\
\hline & 2 & 22 & 16 & 10 & 3 & 1 & 7 & \\
\hline & 3 & 3 & 6 & 2 & 1 & 0 & 1 & \\
\hline & 4 & 2 & 4 & 1 & 0 & 0 & 0 & \\
\hline & 5 & 2 & 1 & 0 & 0 & 0 & 2 & \\
\hline
\end{tabular}




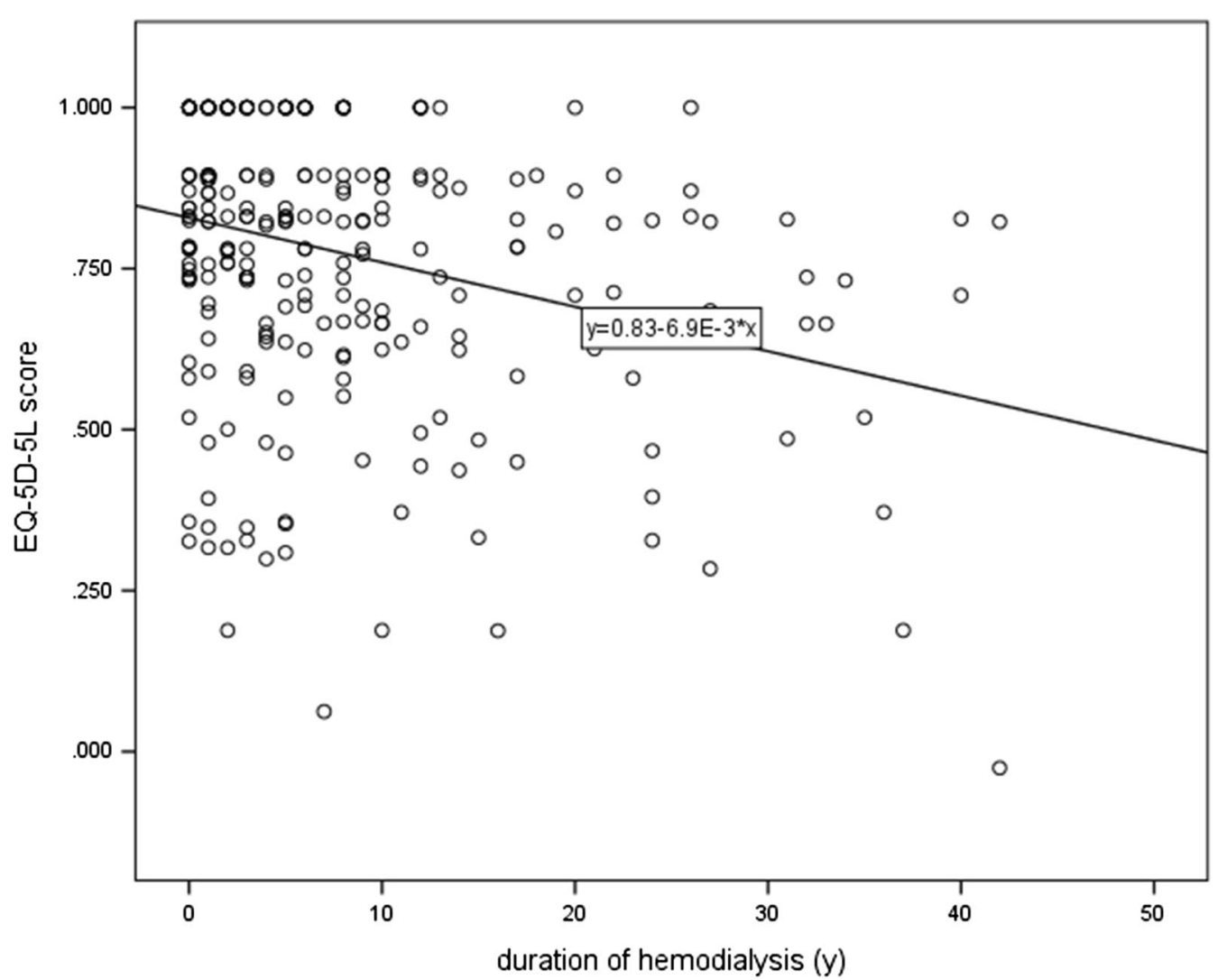

Fig. 2 Scatter plot of duration of hemodialysis and EQ-5D-5L score

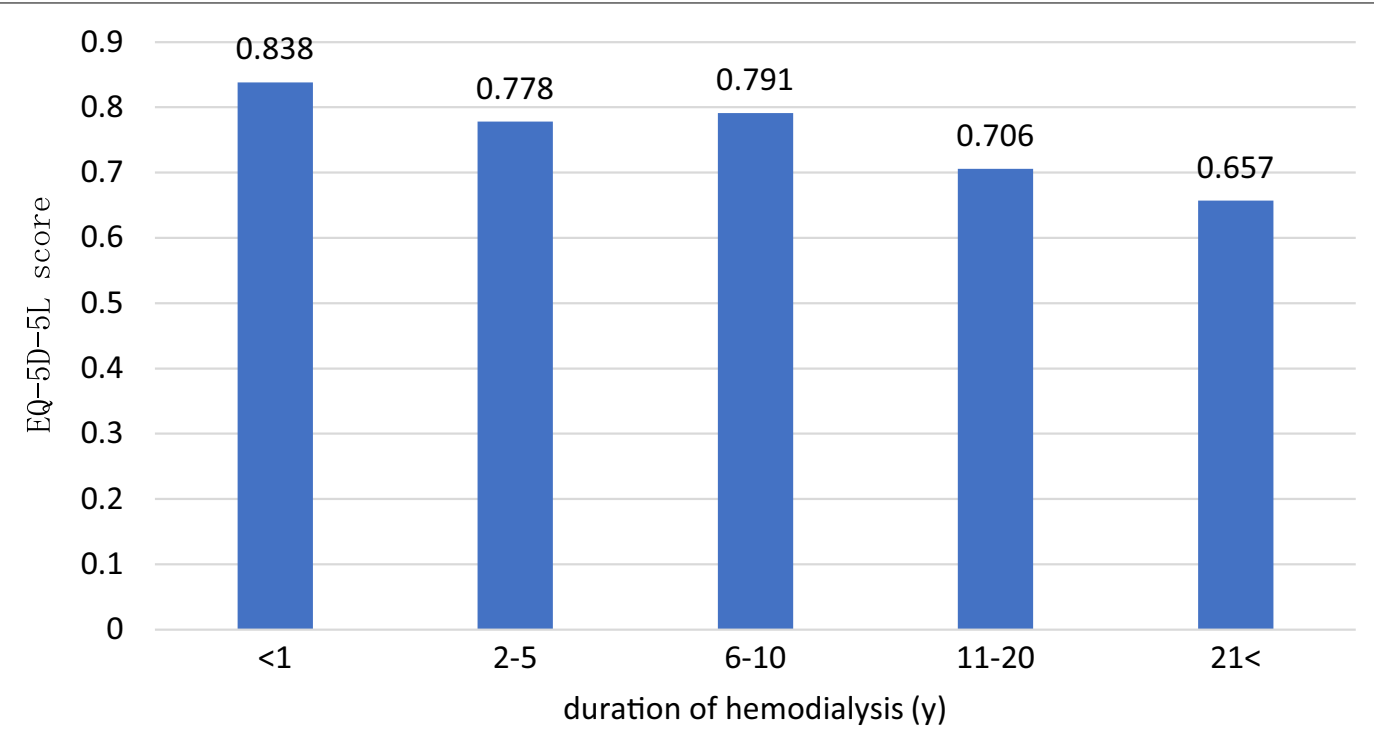

Fig. 3 EQ-5D-5L score by duration of hemodialysis

a significant effect as an explanatory variable (Table 4). In contrast, the EQ-5D-5L VAS score was not significantly affected by any of the explanatory variables (Table 5).

\section{Discussion}

In a 2016 survey conducted by the National Kidney Disease Council of Japan on primary diseases affecting 
Table 3 EQ-5D-5L score between duration of hemodialysis*

\begin{tabular}{llllll}
\hline $\begin{array}{l}\text { Duration of } \\
\text { hemodialysis (y) }\end{array}$ & $\boldsymbol{n}$ & Mean & SD & $\mathbf{9 5 \% C l}$ & \\
\hline$<1$ & 75 & 0.838 & 0.185 & 0.795 & 0.880 \\
$2-5$ & 73 & 0.778 & 0.222 & 0.724 & 0.830 \\
$6-10$ & 59 & 0.791 & 0.191 & 0.739 & 0.841 \\
$11-20$ & 38 & 0.706 & 0.227 & 0.627 & 0.783 \\
$21<$ & 29 & 0.657 & 0.240 & 0.565 & 0.748 \\
\hline
\end{tabular}

$S D$ standard deviation, *significant differences between duration of hemodialysis by one-way ANOVA $(p=0.001)$

Table 4 Regression analysis for EQ-5D-5L score

\begin{tabular}{lrrrrr}
\hline & \multicolumn{1}{l}{$\boldsymbol{B}$} & \multicolumn{1}{c}{$\boldsymbol{T}$} & $\boldsymbol{P}$ value & \multicolumn{1}{c}{$\mathbf{9 5} \boldsymbol{C l}$} & \\
\hline Constant & 0.828 & 9.36 & $<0.001$ & 0.653 & 1.001 \\
Sex & 0.041 & 1.48 & 0.139 & -0.013 & 0.097 \\
Age & -0.001 & -0.89 & 0.373 & -0.003 & 0.001 \\
Diagnosis & 0.000 & 0.03 & 0.978 & -0.017 & 0.017 \\
Duration & $\mathbf{- 0 . 0 0 6}$ & -4.04 & $<0.001$ & $-\mathbf{0 . 0 0 9}$ & $\mathbf{- 0 . 0 0 3}$ \\
\hline
\end{tabular}

$B$ regression coefficient, $T \mathrm{t}$-statics, Boldness suggests statistical significance

Table 5 Regression analysis for EQ-5D-5L VAS

\begin{tabular}{llrrrr}
\hline & \multicolumn{1}{l}{$\boldsymbol{B}$} & \multicolumn{1}{l}{$\boldsymbol{T}$} & $\boldsymbol{P}$ value & \multicolumn{1}{c}{$\mathbf{9 5 \%} \mathbf{C l}$} & \\
\hline Constant & 88.509 & 9.01 & $<0.001$ & 69.127 & 107.891 \\
Sex & -3.537 & -0.87 & 0.281 & -0.343 & 2.919 \\
Age & -0.104 & -0.87 & 0.387 & -3.582 & 0.133 \\
Diagnosis & -1.682 & -1.75 & 0.082 & -0.714 & 0.218 \\
Duration & $-\mathbf{0 . 3 7 4}$ & -2.16 & 0.032 & $\mathbf{- 0 . 7 1 4}$ & $-\mathbf{0 . 0 3 2}$ \\
\hline
\end{tabular}

$B$ regression coefficient, $T$ t-statics, Boldness suggests statistical significance

dialysis patients [15], chronic glomerulonephritis, diabetic nephropathy, nephropathy, nephrosclerosis, cystic kidney, and pregnancy toxemia were reported in $36.0 \%$, $32.5 \%, 10.2 \%, 4.9 \%, 4.9 \%$, and $0.6 \%$ of subjects, respectively. Subjects of that study could be considered representative of the Japanese population.

When using EQ-5D-5L to compare the QOL of dialysis patients with that of healthy Japanese subjects, a survey by Shiroiwa et al. [16] reported scores of 0.939, 0.899, and 0.841 in the age groups of $\sim 59$ years, $60-69$ years, and 70 years or older, respectively, with differences of 0.134 and 0.151 in the age groups of $\sim 59$ and $60-69$ years, respectively. The difference was smaller in the 70 years and older age group (0.062). From this comparison, it can be inferred that the disease burden of dialysis is higher in younger people.

A study that used the Kidney Disease QOL Instrument (KDQOL) to compare the disease burdens of dialysis patients in Japan, Europe, and the United States [17] found that Japanese dialysis patients reported the highest physical function but also had the highest disease burden. The parameters used to assess the burden of disease, as measured using the KDQOL, included whether the subject's kidney disease interferes with their life, takes too much of their time, makes them feel frustrated, or makes them feel like a burden on their family. This is noteworthy, although KDQOL findings cannot simply be compared with QOL measured using the EQ-5D-5L because it asks about the burden on their families. This may be associated with a lower burden of disease according to the KDQOL, but we could not confirm the evidence for this in Japan.

When compared with foreign reports that used the EQ-5D-5L, a higher percentage of respondents reported the most problems with the pain/discomfort dimension, which was similar to the results of our study $[18,19]$. This suggests that in dialysis patients, pain/discomfort, which is the most subjective dimension related to dialysis, may still be a significant problem. In a survey of symptoms experienced by dialysis patients, Abdel-Kader et al. [20] reported that tiredness or lack of energy, worry, dry skin, itchiness, trouble staying asleep, trouble falling asleep, sadness, irritability, difficulty with sexual arousal, bone or joint pain, muscle cramps, anxiousness, etc., were high in dialysis patients. Claxton et al. [21] reported that symptoms such as bone/joint pain, sleeplessness, worry, sadness, nausea, anxiety, and nervousness were frequently observed. These common symptoms were considered to be expressed in the pain/discomfort dimension of the EQ-5D-5L. Although this study showed a decrease in the mobility dimension, many studies [22-27] showed a relationship between muscle weakness and exercise capacity in hemodialysis patients, and it was considered a QOL characteristic. In addition, the negative impact was more profound in the usual activity dimension than in the selfcare dimension, hinting at the current situation in which hemodialysis patients have difficulty participating in society.

According to a study by Li et al. [17], which used the EQ-5D-5L to examine the QOL of patients before kidney transplantation, the mean utility value score was 0.773 , which was close to our study results and those of similar foreign reports, although there were differences in the scoring algorithms used to calculate these results. In studies by Shimizu et al. [13] and Takura et al. [11], the mean scores were 0.738 and $0.76-0.71$, respectively, indicating that patients with kidney disease could maintain their QOL on dialysis. Moreover, this well-maintained QOL remained unaffected by diagnosis and age. Although QOL decreased with an increase in the duration of hemodialysis, the overall impact was 
small. These results suggest that although the preference-based QOL of hemodialysis patients is affected by the duration of dialysis, the effect is not significant, and it is likely to be maintained with less influence from other factors. However, it remains unclear why the QOL is affected, although slightly, by the duration of hemodialysis, and this is a subject of future research.

This study has three major implications. The first was to clarify the effect to dimension of QOL in hemodialysis patients. In addition to the previously reported dimension of mobility and pain, we found that usual activity was also affected. Second, we could collect sufficient data with the EQ-5D-5L for health economic evaluation. Cost-effectiveness analysis assesses an outcome called Quality-Adjusted Life Year (QALY), and the QALY possibly represents healthrelated QOL, i.e., utility values measured on a preference-based measure. In Japan, this scale is limited to the EQ-5D-5L. Therefore, the results of this study can be used for future cost-effectiveness analysis. Third, we clarified the factors that affect the health-related QOL of hemodialysis patients. The results of multiple regression analysis showed that only the duration of hemodialysis was a significant variable, and its effect was not large, suggesting that it is influenced by a combination of factors such as age and disease. Looking from a different perspective, we found that hemodialysis may positively influence the gain in QALY, which is a product of utility value and survival time, as it is the flip side of the long-term maintenance of health-related QOL. In other words, the utility value for hemodialysis patients is independent of disease and age and is maintained over the long term. This suggests that a large QALY gain can be expected in such cases and that efficiency in cost-effectiveness may be appealing.

This study had limitations. As this study was conducted at a single institution, whether the findings are representative of all dialysis patients in Japan is questionable. This was refuted by the fact that the disease rates in the previous national survey were similar. In addition, the dialysis patients' symptoms, comorbidity and other demographic factors (income, job, marital status, et al.) were not included as survey items; thus, the relationships between the factors and QOL could not be clarified. Since there seems to be a causal relationship between symptoms experienced by dialysis patients and QOL assessed using the EQ-5D-5L, future studies should be used to clarify this relationship. In future, we plan to perform studies with higher numbers of cases and analyze changes in QOL over time.

\section{Conclusion}

We investigated the QOL of Japanese hemodialysis patients and the impact of hemodialysis on their EQ5D-5L scores. We found that prolonged hemodialysis decreased QOL. The measured QOL scores were comparable to those of previous studies conducted overseas. The results of our study will be useful for evaluating the cost-effectiveness of dialysis treatment in the future.

\section{Acknowledgements \\ The authors thank all the respondents to this study. \\ Authors' contributions \\ SN, MM, and SS conceived the study and participated in its design. SN performed the statistical analysis and drafted the manuscript. SN, MM, and SS examined and revised the manuscript.}

\section{Funding}

This study was funded by Grant-in-Aid for Scientific Research (KAKENHI) from the Japan Society for the Promotion of Science (26293116).

\section{Availability of data and materials}

The datasets used for this study are available from the corresponding author upon request.

\section{Declarations}

Ethics approval and consent to participate

All procedures performed in this study were in accordance with the ethical standards of the institutional and/or national research committee and with the 1964 Declaration of HELSINKI and its later amendments or comparable ethical standards. This article does not describe any animal studies. This study was approved by the Ethics Committee of Niigata University of Health and Welfare (No. 17560-150205)

\section{Consent for publication}

Not applicable.

\section{Completing interests}

The authors declare that they have no competing interests.

\section{Author details}

${ }^{1}$ Department of Rehabilitation, Niigata University of Health and Welfare, 1398 Shimamicho, Kita-ku, Niigata 950-1398, Japan. ${ }^{2}$ Saiwaicho Memorial Hospital, 3-57 Oomotoekimae, Kita-ku, Okayama 700-0923, Japan. ${ }^{3}$ Department of Nephrology, Rheumatology, Endocrinology and Metabolism, Okayama University, 2-5-1 Shikata-cho, Kita-ku, Okayama 7008558, Japan. ${ }^{4}$ Graduate School of Health Sciences, Okayama University, 2-5-1 Shikata-cho, Kita-ku, Okayama 7008558, Japan.

Received: 14 February 2021 Accepted: 27 October 2021

Published online: 03 November 2021

\section{References}

1. Ando R. The future of dialysis considering the "2025 problem." Jpn J Clin Dial. 2018;34:1401-8 ((in Japanese)).

2. Liem YS, Bosch JL, Hunink MG. Preference-based quality of life of patients on renal replacement therapy: a systematic review and meta-analysis. Value Health. 2008;11:733-41. https://doi.org/10.1111/j.1524-4733.2007. 00308.x.

3. Heidenheim AP, Muirhead N, Moist L, Lindsay RM. Patient quality of life on quotidian hemodialysis. Am J Kidney Dis. 2003;42:36-41. https://doi.org/ 10.1016/s0272-6386(03)00536-5. 
4. Sekercioglu N, Curtis B, Murphy S, Blackhouse G, Barrett B. Estimates of health utility scores in chronic kidney disease. Int Urol Nephrol. 2017:49(11):2043-9. https://doi.org/10.1007/s11255-017-1664-1.

5. Yang F, Lau T, Lee E, Vathsala A, Chia KS, Luo N. Comparison of the preference-based EQ-5D-5L and SF-6D in patients with end-stage renal disease (ESRD). Eur J Health Econ. 2015;16(9):1019-26. https://doi.org/10. 1007/s10198-014-0664-7.

6. Chen JY, Wan EYF, Choi EPH, Chan AKC, Chan KHY, Tsang JPY, Lam CLK. The health-related quality of life of Chinese patients on hemodialysis and peritoneal dialysis. Patient. 2017;10:799-808. https://doi.org/10.1007/ s40271-017-0256-6.

7. Phair G, Agus A, Normand C, Brazil K, Burns A, Roderick P, Maxwell AP, Thompson C, Yaqoob M, Noble H. Healthcare use, costs and quality of life in patients with end-stage kidney disease receiving conservative management: results from a multi-centre observational study (PACKS). Palliat Med. 2018:32:1401-9. https://doi.org/10.1177/0269216318775247.

8. Yang F, Griva K, Lau T, Vathsala A, Lee E, Ng HJ, Mooppil N, Foo M, Newman SP, Chia KS, Luo N. Health-related quality of life of Asian patients with end-stage renal disease (ESRD) in Singapore. Qual Life Res. 2015;24:216371. https://doi.org/10.1007/s11136-015-0964-0.

9. Yang F, Luo N, Lau T, Yu ZL, Foo MWY, Griva K. Health-related quality of life in patients treated with continuous ambulatory peritoneal dialysis and automated peritoneal dialysis in Singapore. Pharmacoecon Open. 2018;2:203-8. https://doi.org/10.1007/s41669-017-0046-z.

10. Herdman M, Gudex C, Lloyd A, et al. Development and preliminary testing of the new five-level version of EQ-5D (EQ-5D-5L). Qual Life Res. 2011:20:1727-36. https://doi.org/10.1007/s11136-011-9903-x.

11. Shiroiwa T, Fukuda T, Ikeda S, et al. Development of an official guideline for the economic evaluation of drugs/medical devices in Japan. Value Health. 2017;20:372-8. https://doi.org/10.1016/j.jval.2016.08.726.

12. Takura T, Nakanishi T, Kawanishi H, Nitta K, Akizawa T, Hiramatsu M, Kawasaki T, Kukita K, Soejima H, Hirakata H, Yoshida T, Miyamoto T, Takahashi S. Cost-effectiveness of maintenance hemodialysis in Japan. Ther Apher Dial. 2015;19:441-9. https://doi.org/10.1111/1744-9987.12314.

13. Shimizu U, Aoki H, Sakagami M, Akazawa K. Walking ability, anxiety and depression, significantly decrease EuroQol 5-dimension 5-level scores in older hemodialysis patients in Japan. Arch Gerontol Geriatr. 2018;78:96100. https://doi.org/10.1016/j.archger.2018.06.006.

14. Ikeda S, Shiroiwa T, Igarashi I, Noto S, Fukuda T, Saito S, et al. Developing a Japanese version of the EQ-5D-5L value set. J Natl Inst Public Health. 2015;64:47-55 ((in Japanese)).

15. The National Kidney Disease Council of Japan. Report on hemodialysis patients'status survey 2016. (in Japanese).

16. Shiroiwa T, Fukuda T, Ikeda S, et al. Japanese population norms for preference-based measures: Eq-5d-3l, Eq-5d-5l, and Sf-6d. Qual Life Res. 2016;25:707-19. https://doi.org/10.1007/s11136-015-1108-2.
17. Fukuhara S, Lopes AA, Bragg-Gresham JL, Kurokawa K, Mapes DL, Akizawa $T$, et al. Health-related quality of life among dialysis patients on three continents: the Dialysis Outcomes and Practice Patterns Study. Kidney Int. 2003;64:1903-10. https://doi.org/10.1046/j.1523-1755.2003.00289.x.

18. Li B, Cairns JA, Draper H, Dudley C, Forsythe JL, et al. Estimating healthstate utility values in kidney transplant recipients and waiting-list patients using the EQ-5D-5L. Value Health. 2017;20:976-84. https://doi.org/10. 1016/j.jval.2017.01.011.

19. Thaweethamcharoen T, Noparatayaporn P, Sritippayawan S, Aiyasanon N. Kidney disease-specific scores and health utility of continuous ambulatory peritoneal dialysis and automated peritoneal dialysis patients and their caregivers. Value Health Reg Issues. 2019;18:59-64. https://doi.org/ 10.1016/j.vhri.2019.12.001.

20. Abdel-Kader K, Unruh ML, Weisbord SD. Symptom burden, depression, and quality of life in chronic and end-stage kidney disease. Clin J Am Soc Nephrol. 2009:4:1057-64. https://doi.org/10.2215/CJN.00430109.

21. Claxton RN, Blackhall L, Weisbord SD, Holley JL. Undertreatment of symptoms in patients on maintenance hemodialysis. J Pain Symptom Manag. 2010;39:211-8. https://doi.org/10.1016/j.jpainsymman.2009.07.003.

22. Watson EL, Baker LA, Wilkinson TJ, Gould DW, Graham-Brown MPM, et al. Reductions in skeletal muscle mitochondrial mass are not restored following exercise training in patients with chronic kidney disease. FASEB J. 2020;34:1755-67. https://doi.org/10.1096/f..201901936RR.

23. Roshanravan B, Gamboa J, Wilund K. Exercise and CKD: skeletal muscle dysfunction and practical application of exercise to pre-vent and treat physical impairments in CKD. Am J Kidney Dis. 2017;69:837-52. https:// doi.org/10.1053/j.ajkd.2017.01.051.

24. Morishita S, Tsubaki A, Shirai N. Physical function was related to mortality in patients with chronic kidney disease and dialysis. Hemodial Int. 2017;21:483-9. https://doi.org/10.1111/hdi.12564.

25. Heiwe $\mathrm{S}$, Jacobson SH. Exercise training in adults with CKD: a systematic review and meta-analysis. Am J Kidney Dis. 2014;64:383-93. https://doi. org/10.1053/j.ajkd.2014.03.020.

26. Hiraki K, Yasuda T, Hotta C, et al. Decreased physical function in pre-dialysis patients with chronic kidney disease. Clin Exp Nephrol. 2013;17:22531. https://doi.org/10.1007/s10157-012-0681-8.

27. Roshanravan B, Robinson-Cohen C, Patel KV, et al. Association between physical performance and all-cause mortality in CKD. J Am Soc Nephrol. 2013;24:822-30. https://doi.org/10.1681/ASN.2012070702.

\section{Publisher's Note}

Springer Nature remains neutral with regard to jurisdictional claims in published maps and institutional affiliations.

Ready to submit your research? Choose BMC and benefit from:

- fast, convenient online submission

- thorough peer review by experienced researchers in your field

- rapid publication on acceptance

- support for research data, including large and complex data types

- gold Open Access which fosters wider collaboration and increased citations

- maximum visibility for your research: over 100M website views per year

At $\mathrm{BMC}$, research is always in progress.

Learn more biomedcentral.com/submissions 